\title{
Fibrinogen Kaiserslautern III: A New Case of Congenital Dysfibrinogenemia with Aa 16 Arg $\rightarrow$ Cys Substitution
}

\author{
R.M. Loreth ${ }^{\mathrm{a}}$ M. Meyer ${ }^{\mathrm{b}} \quad$ F.W. Albert ${ }^{\mathrm{a}}$ \\ aThird Department of Medicine, Clinical Haemostaseology, Westpfalz-Klinikum, \\ Kaiserslautern, and bepartment of Medical Engineering, FH Jena, Germany
}

\section{Key Words}

Dysfibrinogenemia · Fibrinogen · Fibrinogen variant - Mutation - Fibrinopeptide A .

Bleeding tendency

\begin{abstract}
An abnormal fibrinogen was identified in a man with suspicious prolonged prothrombin time and a mild bleeding tendency. Coagulation studies showed marked prolonged thrombin and reptilase clotting times and a discrepancy between functional fibrinogen test and fibrinogen antigen. The rate of fibrinopeptide $B$ release by thrombin was slightly delayed while the release of fibrinopeptide $A$ was only half the normal amount. DNA sequencing revealed a heterozygous $C$ to $T$ point mutation in position 1202 of exon 2 of the $A \alpha$ chain, resulting in the substitution of Arg $\rightarrow$ Cys at position 16, the thrombin cleav-
\end{abstract}

\begin{tabular}{ll}
\hline KARGER & ( ) 2001 S. Karger AG, Basel \\
0301-0147/01/0311-0012\$17.50/0 \\
$\begin{array}{l}\text { E-Mail karger@karger.ch } \\
\text { www.karger.com }\end{array}$ & $\begin{array}{l}\text { Accessible online at: } \\
\text { www.karger.com/journals/hae }\end{array}$
\end{tabular}

age site. This mutation was found also in his 2 children. Both had a mild bleeding tendency too.

$$
\text { Copyright @ } 2001 \text { S. Karger AG, Basel }
$$

\section{Introduction}

More than 250 cases of congenital dysfibrinogenemia have been reported so far. At least half of them were asymptomatic and detected accidentally by pathologic results in routine coagulation tests [1]. Laboratory results involve abnormal thrombin and reptilase clotting time by impaired fibrinopeptide release, abnormal fibrin polymerization or abnormality in fibrin stabilization. One quarter of the patients had a bleeding tendency, a further quarter had a tendency to thrombosis. Most structural defects in the fibrinogen molecule are localized at the thrombin

\footnotetext{
Dr. med. Ralph M. Loreth

Westpfalz-Klinikum GmbH, Medizinische Klinik III

Klinische Hämostaseologie, Hellmut Hartert-Strasse 1

D-67653 Kaiserslautern (Germany)

Tel./Fax +49 631203 1433, E-Mail Ralph.Loreth@t-online.de
} 
Table 1. Coagulation results

\begin{tabular}{|c|c|c|c|c|c|c|c|}
\hline Test & Method/Instrument ${ }^{1}$ & & $\begin{array}{l}\text { Normal } \\
\text { value }\end{array}$ & $\begin{array}{l}\text { ME } \\
\text { (patient) }\end{array}$ & $\begin{array}{l}\text { MC } \\
\text { (son) }\end{array}$ & $\begin{array}{l}\text { MH } \\
\text { (daughter) }\end{array}$ & $\begin{array}{l}\text { MI } \\
\text { (normal control) }\end{array}$ \\
\hline Prothrombin time, $\%$ & Innovin $^{\mathrm{a}}$ & Electra $1000^{\mathrm{c}}$ & $70-130$ & 59 & 59 & 84 & 122 \\
\hline $\mathrm{aPTT}, \mathrm{s}$ & Actin $\mathrm{FS}^{\mathrm{a}}$ & Electra $1000^{c}$ & $25-35$ & 28 & 32 & 26 & 24 \\
\hline Thrombin clotting time, $\mathrm{s}$ & Thrombin $1.25 \mathrm{IU}^{\mathrm{b}}$ & Electra $1600^{c}$ & $<20$ & 35 & 40 & 39 & 16 \\
\hline Reptilase clotting time, $\mathrm{s}$ & Fibroclotin ${ }^{\mathrm{a}}$ & Schnitger \& Gross ${ }^{\mathrm{d}}$ & $<20$ & 105 & 71 & 62 & 18 \\
\hline Clottable fibrinogen, $\mathrm{g} / 1$ & Clauss $^{\mathrm{a}}$ & Schnitger \& Gross ${ }^{d}$ & $1.5-4.5$ & 0.26 & 0.26 & 0.27 & 2.9 \\
\hline Fibrinogen antigen, g/l & Nephelometric ${ }^{a}$ & BNA (Behring) ${ }^{\mathrm{a}}$ & $1.8-3.5$ & 1.9 & 2.3 & 2.9 & 2.9 \\
\hline Platelet aggregation & & PAP $4 \mathrm{e}$ & & normal & normal & normal & normal \\
\hline Platelet function analysis & & PFA $100^{a}$ & & normal & normal & normal & normal \\
\hline
\end{tabular}

1 Manufacturers of the reagents and instruments used: ${ }^{\mathrm{a}}$ Dade Behring; ${ }^{\mathrm{b}}$ Roche Diagnostics; ${ }^{\mathrm{c}} \mathrm{MLA} ;{ }^{\mathrm{d}}$ Amelung; ${ }^{\mathrm{e}}$ BioData.

cleavage site in position 16 at the amino-terminal part of the A $\alpha$ chain. Replacement of arginine 16 by histidine is the most common mutation, reported in over 20 families. The replacement of arginine 16 by cysteine has been reported in fewer cases $[2,3]$. In this report we describe another case of congenital dysfibrinogenemia heterozygous for this mutation.

\section{Materials and Methods}

\section{Coagulation Tests}

Blood samples from the patients and normal individuals were collected in trisodium citrate $(0.1 \mathrm{~mol} / \mathrm{l}$ Monovette ${ }^{\circledR}$; Sarstedt) and plasma was separated by centrifugation $\left(2,000 \mathrm{~g} / 20 \mathrm{~min}\right.$ at $\left.21^{\circ} \mathrm{C}\right)$. Plasma was stored at $-70^{\circ} \mathrm{C}$ for further use. Prothrombin time (PT), aPTT, thrombin clotting time (TCT) and reptilase clotting time (RCT) were performed by established procedures. Clottable plasma fibrinogen was measured by the coagulometric method according to Clauss. Fibrinogen antigen levels were determined immunologically. Platelet aggregation was evaluated in platelet-rich plasma by standard procedure (PAP 4 Analyzer, BioData) with ristocetin, collagen, epinephrine and ADP. Platelet function analysis was performed by the PFA $100^{\circledR}$ (Dade) with collagen-epinephrine (PCE) and collagen-ADP (PCA) test cartridges. The reagents and instruments used are listed in table 1. PT was further determined with different thromboplastins as shown in table 2 .

\section{Fibrinogen Purification}

Fibrinogen was purified from frozen citrated plasma as described by Masri et al. [4] with the following modifications: polyethylene glycol 1500 was used as a precipitating agent; $1 \mathrm{mmol} / 1$ phenylmethylsulfonyl fluoride (PMSF) and $0.025 \mathrm{~mol} / \mathrm{l} \varepsilon$-aminocaproic acid were used in all solutions during the isolation procedure.

\section{Fibrinopeptide Release}

Citrate-buffered solutions of purified fibrinogen containing $3 \mathrm{mg} / \mathrm{ml}$ protein were incubated with 5 $\mathrm{NIH}$ units bovine thrombin/ml at $37^{\circ} \mathrm{C}$ for 1,5 and $20 \mathrm{~min}$. At the times indicated, thrombin activity was inhibited by addition of 15 units $/ \mathrm{ml}$ hirudin, $0.3 \mathrm{mmol} / \mathrm{l} \mathrm{PMSF}$ and $1 \%(\mathrm{w} / \mathrm{v})$ sodium dodecyl sulfate. Samples were incubated at $100^{\circ} \mathrm{C}$ for $5 \mathrm{~min} .3 \%$ $(w / v)$ dithiothreitol was added to aliquots of these samples, boiled for $3 \mathrm{~min}$ and loaded onto $8 \%(\mathrm{w} / \mathrm{v})$ polyacrylamide gels. Electrophoresis was performed according to Laemmli [5]. For evaluation, gels were stained with Coomassie blue.

\section{Isolation of DNA and Mutation Analysis}

Genomic DNA was isolated from EDTA-anticoagulated whole blood by hypotonic lysis of blood cells followed by treatment with proteinase $\mathrm{K}$ according to a standard protocol. DNA sequences coding for the Nterminal part of the fibrinogen A $\alpha$ gene (nt 1105-1324) were amplified from genomic DNA by PCR using the following primers: 5'-GCT AAC ATT GCT GTT GCT CTC-3' (forward) and 5'-GCA TCA GAG GGA AGG AAT CTC-3' (reverse). The reverse primer was 5'-biotinylated. Single strands were prepared after binding biotinylated PCR products to streptavidin-coated 
Table 2. PT expressed as ratio with different reagents

\begin{tabular}{|c|c|c|c|c|}
\hline Reagent $^{1}$ & $\begin{array}{l}\mathrm{ME} \\
\text { (patient) } \\
\mathrm{E} / \mathrm{S} \& \mathrm{G}^{2}\end{array}$ & $\begin{array}{l}\mathrm{MC} \\
\text { (son) } \\
\text { E/S\&G }\end{array}$ & $\begin{array}{l}\text { MH } \\
\text { (daughter) } \\
\text { E/S\&G }\end{array}$ & $\begin{array}{l}\text { MI } \\
\text { (normal control) } \\
\text { E/S\&G }\end{array}$ \\
\hline Innovin a (Dade Behring) & $1.39 / 1.77$ & $1.41 / 1.78$ & $1.06 / 1.31$ & $0.95 / 0.98$ \\
\hline RecombiPlasTin ${ }^{a}$ (Ortho) & n.a./1.53 & n.a./1.46 & n.a./1.24 & n.a./1.04 \\
\hline Neoplastin Plus ${ }^{\mathrm{b}}$ (Roche Diagnostics) & $1.22 / 1.79$ & $1.18 / 1.47$ & $1.09 / 1.44$ & $0.96 / 0.98$ \\
\hline Thromborel Sc (Dade Behring) & $1.10 / 1.27$ & $1.11 / 1.27$ & $1.03 / 1.16$ & $0.98 / 1.00$ \\
\hline PT-FIB HS ${ }^{b}$ (IL) & $1.10 / 1.30$ & $1.13 / 1.32$ & $1.01 / 1.14$ & $0.98 / 1.03$ \\
\hline
\end{tabular}

Source of thromboplastin: ahuman recombinant; ${ }^{b}$ rabbit brain; chuman placenta.

2 Coagulation instruments: E: Electra 1600 (MLA); S\& G: Schnitger \& Gross (Amelung).

magnetic beads (Dynabeads ${ }^{\circledR}$ ). Sequencing reactions (dideoxy method) were performed using the Sequenase $^{\circledR}$ 7-deaza-dGTP Sequencing Kit (USB). The sequencing primer (5'-GCT GTT GCT CTC TTT TGT GT-3') was 5'-labeled with the infrared fluorescent dye IRD-41. Sequences were read in a LICOR Automated DNA Sequencer Model 4000.

\section{Results}

\section{Case Report}

The propositus was a 50-year-old Caucasian man (ME). He was referred to our ward with suspicious prolonged PT (Quick 38\%/ normal value 70-120\%). In his history he had sometimes had mild bleeding from the gums and a stronger bleeding after tooth extraction 7 years ago. He got over a fracture of the base of his skull at the age of 9 years and several operations (meniscectomy) years ago without bleeding complications. In his family his 48year-old sister (MI) had no bleeding tendency in her history. His 23-year-old son (MC) had a history of often nose and gingival bleeding but he overcame herniorrhaphy and meniscectomy some years ago without bleeding complications. His 26-year-old daughter ( $\mathrm{MH})$ often had hematoma formation even after a mild injury, bleeding from the gums, delayed wound healing and a prolonged and stronger menstrual bleeding.

\section{Coagulation Results}

The coagulation results are shown in tables 1 and 2 . In 2 of the 3 family members (ME, MC, MH) heterozygous for the mutation A $\alpha$ Arg $\rightarrow$ Cys, the PT was markedly prolonged. Other causes of the mild bleeding tendency in this family as a defect in primary hemostasis or a deficiency of coagulation factors could be ruled out by coagulation studies (data not shown). PT measured using various reagents demonstrated different sensitivity for this fibrinogen variant. Highest sensitivity was found using a recombinant reagent (Innovin $^{\circledR}$, Dade Behring) on a mechanical instrument (Schnitger \& Gross).

\section{Fibrinopeptide Release}

In the fibrinopeptide release study of samples from ME, MH and MC, only about half of the A $\alpha$ chains were cleaved by thrombin within $1 \mathrm{~min}$. The second half of the A $\alpha$ chains remained uncleaved even after a 20min thrombin treatment. The release of fibrinopeptide B in these samples appeared slight- 
Control

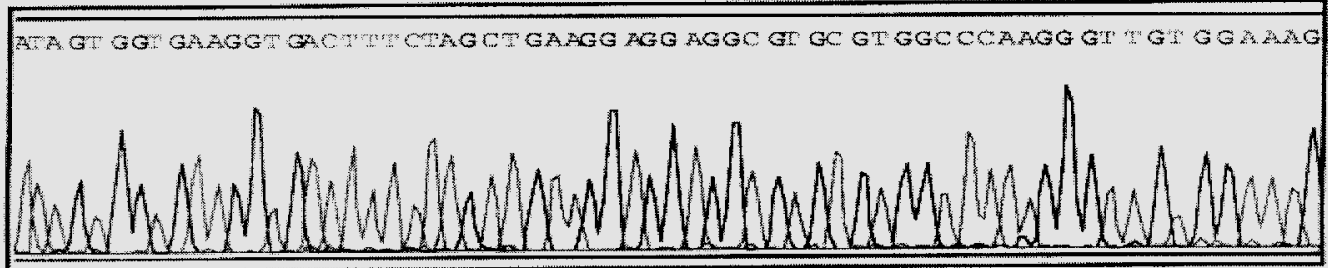

Patient ME

$\mathrm{nt} 1202 \mathrm{C} \rightarrow \mathrm{T}$

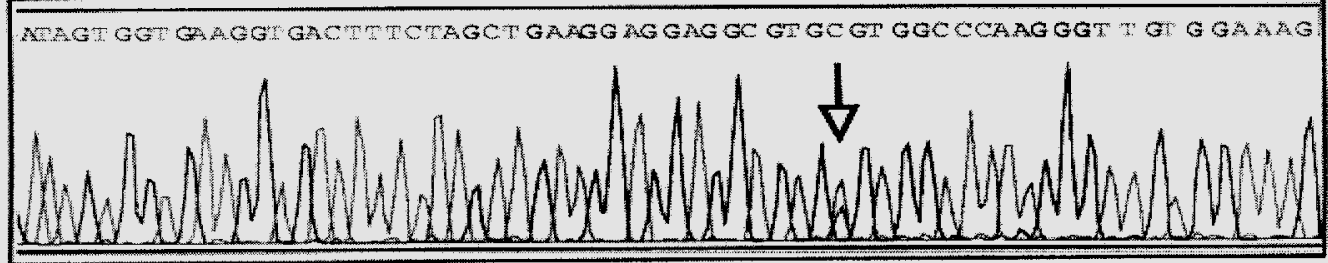

Patient $\mathrm{MH}$

$n t 1202 \mathrm{C} \rightarrow \mathrm{T}$

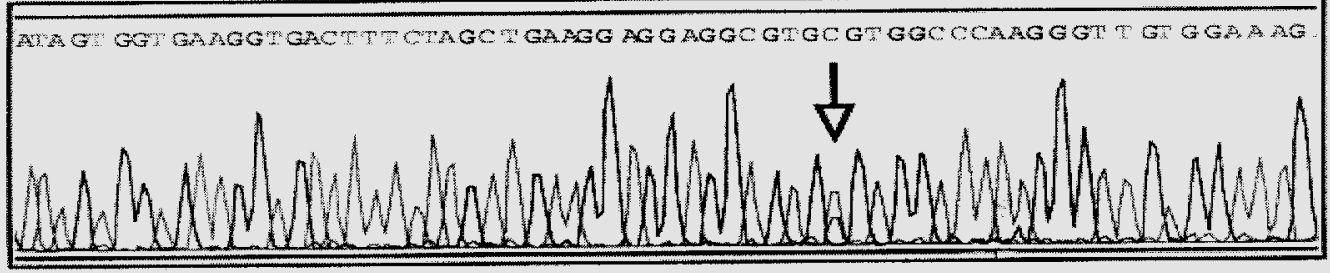

Patient MI (normal)

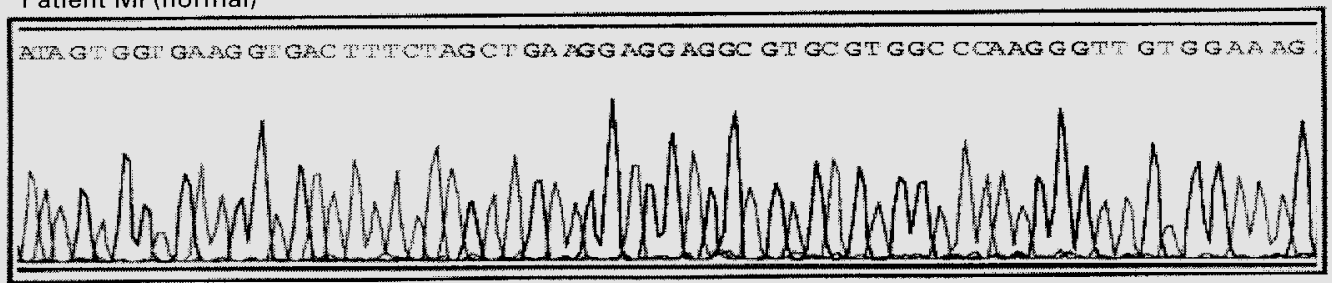

Fig. 1. Sequencing of the PCR product. Sequencing reactions (dideoxy method) were performed using the Sequenase ${ }^{\circledR}$ 7-deaza-dGTP Sequencing Kit (USB). The sequencing primer (5'-GCT GTT GCT CTC TTT TGT GT-3') was 5'-labeled with IRD-41. Sequences were read in a LICOR Automated DNA Sequencer Model 4000. Results are shown for control, the 2 heterozygous patients $\mathrm{ME}$ and $\mathrm{MH}$, and the normal patient MI. 
ly delayed but was completed after $20 \mathrm{~min}$ thrombin treatment. The fibrinopeptide A and fibrinopeptide B release in the sample from MI was like in a normal control. It should be mentioned that only SDS-PAGE was used to evaluate the thrombin cleavage.

\section{DNA Amplification and Sequencing}

Amplification of exon 2 of the fibrinogen A $\alpha$ gene coding for the N-terminal part of the protein followed by sequencing of the resulting PCR products revealed the missense mutation $\mathrm{C}$ to $\mathrm{T}$ in position 1202 (fig. 1). This base exchange is responsible for a replacement of Arg16 by Cys. All 3 patients were found heterozygous for this mutation. In the sample from MI, the mutation was absent.

\section{Discussion}

Fibrinogen Kaiserslautern III is a functionally abnormal fibrinogen variant generally noticed by chance due to a suspicious prolonged PT. Further coagulation studies also revealed a moderate prolonged TCT and a markedly prolonged RCT. Clottable fibrinogen was found very low, while the fibrinogen antigen was in the normal range. In the fibrinopeptide release study, thrombin releases only half of the fibrinopeptide A. The fibrinopeptide B was cleaved completely, but cleavage was slightly delayed. Genomic analysis detected a heterozygous mutation $\mathrm{C}$ to $\mathrm{T}$ in position 1202 of the A $\alpha$ gene leading to the replacement of arginine by cysteine at the thrombin cleavage site of the A $\alpha$ chain. This mutation was found in 3 family members. All of them had a mild bleeding tendency in their history, while the 1 member of the family without this mutation did not suffer from bleeding.

As thrombin or reptilase is unable to cleave fibrinopeptide A with cysteine in position 16, a heterozygous mutation explains the results in the fibrinopeptide release study. The delayed cleavage of the fibrinopeptide B may result from a delayed fibrin polymerization caused by the uncleaved abnormal fibrinopeptide A. As fibrinopeptide A cleavage is reported not to depend of fibrin polymerization, normally cleavage of fibrinopeptide $B$ becomes accelerated by fibrin polymerization $[6,7]$.

PT reagents differ in their sensitivity for this fibrinogen variant. Highest sensitivity was found with the two recombinant thromboplastin preparations and one of rabbit brain source. These differences are possibly caused by the different sensitivity, source and matrix of these reagents. Higher sensitivity was also found by using a mechanical detecting system compared to an optical analyzer. The mechanical system seems to be more susceptible for an initially slower and looser clot formation as it should be in this fibrinogen variant. In MH the PT was not delayed, although the mutation was present. This may be due to an elevated factor VII activity found in this person (data not shown).

A substitution of $A \alpha \operatorname{Arg} 16$ to Cys has been reported earlier in several cases. Fibrinogen Metz [8] is a homozygous variant as Bergamo I [9], Kawaguchi [10], Osaka I [10], Stony Brook [11], Ledyard [12] and Torino [13] are heterozygous variants. Fibrinogen Metz is the only known case in which fibrin formation can occur even in the absence of fibrinopeptide A release. Fibrinogens Kawaguchi and Osaka I have been shown to have the Cys16 bound to the Cys16 in the same molecule. Thus in these cases, homodimers are formed. Until now, this could not be confirmed for fibrinogen Kaiserslautern III. For Bergamo I, fibrinopeptide B release was reported normal, while in fibrinogen Kaiserslautern III in contrast, it was slightly delayed. In fibrinogen Stony Brook a decreased platelet aggregation was observed. For the variant Kaiserslau- 
tern III, we could demonstrate normal platelet aggregation and normal primary hemostatic capacity. The patients with fibrinogen variants Kawaguchi, Osaka I, Stony Brook and Torino are reported to be asymptomatic. The 3 patients with fibrinogen Kaiserslautern III had a history of mild bleeding tendency, while family members without this mutation had no history of bleeding complications.

\section{Acknowledgment}

The authors are grateful for the skilled assistance extended by their laboratory staff.

\section{References}

1 Haverkate F, Samama M: Familial dysfibrinogenemia and thrombophilia: Report on a study of the SCC subcommittee on fibrinogen. Thromb Haemost 1995;73: 151-161.

2 McDonagh J, Carrell N, Lee NH: Dysfibrinogenemia and other disorders of fibrinogen structure and function; in Colman RW, Hirsh J, Marder VJ, Salzman EW (eds): Hemostasis and Thrombosis: Basic Principles and Clinical Practice. Philadelphia, Lippincott, 1994, pp 314-334.

3 Henschen AH: Human fibrinogen Structural variants and functional sites. Thromb Haemost 1993;70: 42-47.

4 Masri MA, Masri SA, Boyd ND: Isolation of human fibrinogen of high purity and in high yield using polyethylene glycol 1000. Thromb Haemost 1983;49:116-119.

5 Laemmli UK: Cleavage of structural proteins during the assembly of the head of bacteriophage T4. Nature 1970;227:680-685.
6 Mosesson MW: Fibrinogen and fibrin polymerization: Appraisal of the binding events that accompany fibrin generation and fibrin clot assembly. Blood Coagul Fibrinolysis 1997;8:257-267.

7 Ruf W, Bender A, Lane DA Preissner KT, Selmayr E, MüllerBerghaus G: Thrombin-induced fibrinopeptide $\mathrm{B}$ release from normal and variant fibrinogens: Influence of inhibitors of fibrin polymerization. Biochim Biophys Acta 1988;965: 169-175.

8 Soria J, Soria C, Samama M: Detection of fibrinogen abnormality in dysfibrinogenemia: Special report of fibrinogen Metz characterized by an amino acid substitution located at the peptide bond cleaved by thrombin; in Henschen A, Graeff H, Lottspeich F (eds): Fibrinogen - Recent Biochemical and Medical Aspects. Berlin, de Gruyter, 1982, p 153.

9 Reber P, Furlan M, Beck EA, Finazzi G, Buelli M, Barbui T: Fibrinogen Bergamo I (A $\alpha$ 16Arg $\rightarrow$ Cys): Susceptibility towards thrombin following aminoethylation, methylation or carboxamidomethylation of cysteine residues. Thromb Haemost 1985;54:390.
10 Miyata T, Terukina S, Matsuda M: Fibrinogens Kawaguchi and Osaka: An amino acid substitution of $\mathrm{A} \alpha$ arginine-16 to cysteine which forms an extra interchain disulfide bridge between the two A $\alpha$ chains. J Biochem (Tokyo) 1987;102:93.

11 Galanakis DK, Henschen A: Aspects of evaluation of fibrinogen Stony Brook: A defect resulting in failure to release peptide $\mathrm{A}$; in Henschen A, Hessel B, McDonagh J, Saldeen $\mathrm{T}$ (eds): Fibrinogen: Structural Variants and Interactions. Berlin, de Gruyter, 1985, pp 207.

12 Lee MH: Fibrinogen Ledyard (Aa Arg16-Cys): Biochemical and physiologic characterization. Blood 1991; 78:1744.

13 Reber P, Furlan M, Beck EA, Barbui T: Fibrinogen Bergamo III and fibrinogen Torino: Two further variants with hereditary molecular defects in fibrinopeptide A. Thromb Res 1987;46:163. 